SUBJECT AREAS:

ANIMAL BEHAVIOUR

EVOLUTIONARY THEORY

COMPUTATIONAL SCIENCE

STATISTICS

SCIENTIFIC REPORTS:

$4: 5604$

DOI: $10.1038 /$ srep05604

(2014)

Published:

15 July 2014

Updated:

29 August 2014

\section{ERRATUM: Using sociometers to quantify social interaction patterns}

Jukka-Pekka Onnela, Benjamin N. Waber, Alex Pentland, Sebastian Schnorf \& David Lazer

There is a typographical error in the 'Proximity' section of this Article. "We repeated our analyses using time windows of various widths and found the results to be remarkably." should read "We repeated our analyses using time windows of various widths and found the results to be remarkably robust". 